\title{
PENGARUH IKLIM ORGANISASI DAN ORGANIZATIONAL CITIZENSHIP BEHAVIOR (OCB) TERHADAP PRODUKTIVITAS
}

\author{
Muslimah* $^{*}$
}

Abstract: The objective of this research is to study information about the effect of organizational climate and organizational citizenship behavior (OCB) on the productivity. Ministry of National Education of Indonesia by using survey method with path analysis applied in testing hypothesis. The sample size in the research was done to 74 headmaster with samples taken using simple random sampling. The data were analyzed by using descriptive analyses, regressive analysis, and line analysis method. The result shows that there are direct influence of the followings: (1) there is positively direct effect of organizational climate on the productivity, (2) there is positively direct effect of organizational citizenship behavior $(O C B)$ on the productivity (3) there is positively direct effect of organizational climate on the organizational citizenship behavior $(O C B)$. It is expected that the results of the research could be implied in increasing and optimalizing the productivity, organizational climate, and organizational citizenship behavior (OCB) should be taken into account.

Keywords: organizational climate, organizational citizenship behavior, productivity.

\section{PENDAHULUAN}

Kualitas pendidikan di Indonesia saat ini sangat memprihatinkan. Ini dibuktikan antara lain dengan data UNESCO (2000) tentang peringkat Indeks Pengembangan Manusia (Human Development Index), yaitu komposisi dari peringkat pencapaian pendidikan, kesehatan, dan penghasilan per-kepala yang menunjukkan bahwa indeks pengembangan manusia Indonesia makin menurun. Di sisi lain, data EFD indeks pembangunan Indonesia pada Tahun 2011 menurun dari peringkat ke 65 ke peringkat 69 dari 127 negara di dunia.

Penyebab rendahnya pendidikan di Indonesia antara lain karena persoalanpersoalan internal yang dihadapi sekolah itu sendiri, seperti kendala lingkungan sekolah, keterbatasan sarana prasarana serta kurangnya dukungan stakeholders dalam penunjang kegiatan pendidikan yang dikelola kepala sekolah. Selain itu, proses pengangkatan kepala sekolah yang tidak transparan yang kemudian lakurang mampu menjalankan tugas dan fungsi secara optimal. Keadaan ini pun terjadi di wilayah Tangerang Raya. kepala sekolah tidak menjalankan tugas dan fungsinya sebagai pemimpin pendidikan, rendahnya mental kepala sekolah yang ditandai dengan kurangnya motivasi dan semangat serta kurangnya disiplin dan tanggung jawab dalam melakukan tugas, tidak memahami pekerjaan, sempitnya wawasan kepala sekolah dan tidak memiliki program kerja sehingga kepala sekolah hanya menjalankan tugas secara konvensional tanpa arah yang jelas untuk mencapai tujuan. Sikap kepala sekolah yang seperti ini lah menyebabkan rendahnya produktivitas kepala sekolah.

Salah satu indikator keberhasilan kepemimpinan seorang kepala sekolah diukur dari mutu pendidikan yang ada di sekolah yang dipimpinnya. Dalam konteks pendidikan, pengertian mutu mencakup input, proses, dan output pendidikan, input

\footnotetext{
* Kepala sekolah di Madrasah Aliyah Nurul Falah Pagedangan- Tangerang
} 
pendidikan adalah segala sesuatu yang harus tersedia karena dibutuhkan untuk berlangsungnya proses. Proses pendidikan merupakan berubahnya sesuatu menjadi sesuatu yang lain dengan mengintegrasikan input sekolah sehingga mampu menciptakan situasi pembelajaran yang menyenangkan (enjoyable learning), mampu mendorong motivasi dan minat belajar, dan benar-benar mampu memberdayakan peserta didik. Output pendidikan adalah merupakan kinerja sekolah yang dapat diukur dari kualitasnya, efektivitasnya, produktivitasnya, efisiensinya, inovasinya, dan moral kerjanya.

Kepala sekolah merupakan salah satu komponen pendidikan yang paling berperan dalam meningkatkan kualitas pendidikan. Interaksi perilaku kewargaan organisasi akan menentukan iklim sekolah yang bagaimana yang akan terwujud. Iklim sekolah yang baik dan kondusif bagi kegiatan pendidikan akan menghasilkan interaksi edukatif yang efektif sehingga pencapaian tujuan pendidikan sekolah akan berjalan baik. Karenanya kepala sekolah sebagai pimpinan organisasi seharusnya menciptakan suasana kerja yang nyaman sehingga iklim organisasi menjadi kekuatan utama dalam meningkatkan produktivitas pendidikan. Kepala sekolah yang profesional akan berfikir untuk membuat perubahan tidak lagi berfikir bagaimana suatu perubahan sebagaimana adanya sehingga tidak terlindas oleh perubahan tersebut.

Ketercapaian tujuan pendidikan sangat bergantung pada kecakapan dan kebijaksanaan kepemimpinan kepala sekolah yang merupakan salah satu pemimpin pendidikan. Karena kepala sekolah merupakan seorang pejabat yang profesional dalam organisasi sekolah yang bertugas mengatur semua sumber organisasi dan bekerjasama dengan guru-guru dalam mendidik siswa untuk mencapai tujuan pendidikan. Padahal tidak dapat disangsikan lagi bahwa tidak ada sekolah/madrasah efektif tanpa dikelola oleh kepala sekolah/madrasah yang efektif dan produktif. Kenyataan dilapangan membuktikan bahwa semua sekolah/madrasah yang produktif atau bermutu tinggi, selalu dikelola oleh kepala sekolah/madrasah yang produktif pula.

Peranan kepala sekolah/madrasah menurut Peraturan Pemerintah Republik Indonesia Nomor 13 tentang Standar Kepala Sekolah/Madrasah adalah sebagai: pribadi, manajer, entrepreneur (primaentrevisi), supervisor dan sosial. Peranan kepala sekolah/madrasah sebagai leader dalam hal ini sudah termasuk dalam peranan kepala sekolah/madrasah sebagai manager karena manager meliputi leader. Demikian pula halnya dengan climate creator yaitu kepala sekolah/madrasah sebagai pencipta budaya dan iklim sekolah/madrasah yang kondusif dan inovatif bagi pembelajaran peserta didik.

Untuk itu seorang kepala sekolah harus didorong semangatnya agar bersedia mencurahkan perhatian, pikiran dan kemampuannya ke dalam pelaksanaan tugastugasnya, sehingga dapat diperoleh hasil kerja yang optimal. Dengan memperhatikan dan memanfaatkan potensi yang ada pada kepala sekolah, perlu digali dan ditumbuhkan, dikembangkan serta ditingkatkan kemampuannya agar pengetahuan dan keterampilan mereka meningkat, sehingga akan mampu melaksanakan tugastugas yang menjadi tanggung jawabnya secara efektif dan efisien yang dengan sendirinya dapat meningkatkan produktivitas. 


\section{Produktivitas}

Menurut John R.Schermerhorn, JR (2010:404) productivity is the quantity and quality of work performance, with resource utilization considered Produktivitas adalah kuantitas dan kualitas kerja dengan pemanfaatan sumber daya yang ada. Dari konsep tersebut dapat dipahami bahwa kuantitas dan kualitas kerja tersebut mengacu kepada produktivitas individu. Produktivitas individu dapat dinilai dari apa yang dilakukan oleh individu tersebut dalam kerjanya. Margaret A. dkk (2002:309) mengemukakan penyebab rendahnya produktivitas adalah "low productivity because individuals are not motivated to be productive" . Produktivitas rendah karena individu tidak termotivasi untuk menjadi produktif.

Menurut Klinger dan Nanbaldian dalam tulisan Faustino Cardoso (2003:160) menyatakan produktivitas merupakan fungsi perkalian dari usaha pegawai (effort) yang didukung dengan motivasi yang tinggi, dengan kemampuan pegawai (ability), yang diperoleh melalui latihan-latihan. Produktivitas yang meningkat berarti performansi yang baik, akan menjadi feedback bagi usaha, atau memotivasi pekerja pada tahap berikutnya. Berdasarkan konsep tersebut dapat dilihat bahwa produktivitas bukan hanya mengukur jumlah keluaran yang dihasilkan sebanyak-banyaknya, akan tetapi lebih dari itu adalah memperhatikan kualitas keluarannya. Dengan kata lain produktivitas adalah bagaimana seseorang dapat melakukan pekerjaannya dengan baik sehingga menghasilkan produk yang baik.

Dalam kehidupan organisasi terdapat sikap mental pekerja yang tidak produktif, menurut Darsono dan Tjatjuk Siswandoko (2011:169) ciri-ciri sikap mentela pekerja yang tidak produktif yaitu: (1). orang-orang yang menganggap bahwa tanpa input yang besar tidak akan dapat menghasilkan output yang besar (2) orang-orang yang merasa puas dengan hasil yang telah diperoleh (3) orang-orang yang tidak perlu berusaha lebih keras lagi padahal kesempatan untuk itu ada (4) orang-orang yang menunda menyelesaikan pekerjaan.

Schermerhorn (2010:485) mengatakan "productivity involves two common performance measures : effectiveness and efficiency" produktivitas melibatkan dua ukuran kinerja yang umum yaitu efektivitas dan efisiensi. Hal ini senada dengan Umar Hussein dalam tulisan Joko Raharjo (2013:63) mengatakan bahwa produktivitas memiliki dua dimensi, dimensi pertama adalah efektivitas (do the right things) melaksanakan sesuatu yang benar dalam memenuhi kebutuhan organisasi yang mengarah kepada pencapaian unjuk kerja yang maksimal yaitu pencapaian target yang berkaitan dengan kualitas, kuantitas, dan waktu. Sedangkan dimensi yang kedua yaitu efisiensi adalah doing things right. Melakukan yang benar dengan proses yang benar berkaitan dengan upaya membandingkan input dengan realisasi penggunaannya atau bagaimana pekerjaan tersebut dilaksanakan. Untuk itu produktivitas biasanya dicapai melalui efektivitas pencapaian tujuan dan efisiensi penggunaan sumber daya. Produktivitas dipandang dalam dua sisi sekaligus yaitu sisi input dan sisi output. Produktivitas tidak sama dengan produksi, tetapi produksi, performansi kualitas, hasil-hasil, merupakan komponen dari usaha produktivitas.

Dengan demikian, produktivitas merupakan suatu kombinasi dari efektivitas dan efisiensi. Dalam usaha mencapai suatu produktivitas yang tinggi seorang kepala sekolah harus mengerahkan segala kemampuan dan keterampilan yang dimilikinya serta sumber daya yang ada di sekolah dengan efektif dan efisien sehingga hasil pekerjaannya sesuai dengan tujuan yang ditetapkan oleh sekolah.

Berdasarkan uraian di atas dapat disintesiskan produktivitas adalah efektivitas dan efisiensi kerja seseorang dalam memanfaatkan sumber daya untuk mencapai hasil 
pekerjaan yang berkualitas dengan indikator ketepatan dalam mengerjakan tugas, kesesuaian dalam penggunaan sumber daya dan rasa tanggung jawab terhadap pekerjaan.

\section{Iklim Organisasi}

Iklim organisasi menurut Rae Andre (2008:446) adalah "climate to refer to organizational members perceptions of an organization's policies, practices, and procedures, including its structure, reward systems, warmth and support, and other aspects". Iklim merujuk kepada persepsi anggota organisasi akan kebijakan organisasi, praktek, dan prosedur, termasuk struktur, sistem penghargaan, kehangatan dan dukungan, dan aspek lainnya. Menurut Stephen P. Robbins dan Timothy A.Judge (2011:58), iklim organisasi adalah," organizational climate refers to the shared perceptions organizational members have about their organization and work environment". Iklim organisasi merujuk pada persepsi-persepsi bersama oleh anggota anggota organisasi tentang organisasi dan lingkungan kerja mereka.

Mullins (2005:900) menyatakan iklim organisasi adalah "organizational climate is an indication of the employees' feelings and beliefs of what the organisation is about". Iklim organisasi merupakan indikasi perasaan dan keyakinan karyawan tentang apa organisasi yang ada. Pengertian ini menyatakan bahwa iklim lebih didasarkan pada persepsi anggota terhadap organisasi. Mullins (2005:899) juga mengemukakan pengaruh iklim organisasi adalah sebagai berikut "organisational climate will influence the level of morale and attitudes which members of the organisation bring to bear on their work performance and personal relationships". Iklim organisasi akan mempengaruhi tingkat moral dan sikap yang anggota organisasi bawa untuk melahirkan kinerja kerja dan hubungan pribadi mereka.

Moral adalah konsep umum yang sulit untuk mengukur secara obyektif. Sesuatu yang dirancang dengan cermat dan survey yang dilakukan dapat membantu untuk membangun perasaan pegawai pada faktor-faktor yang berkontribusi terhadap iklim organisasi. Ketika pegawai merasa moralnya rendah, dalam organisasi maka perasaan frustrasi atau keterasingan akan muncul pada pegawai, penting bahwa tindakan positif harus diambil untuk mengatasi penyebabnya. Moral dapat dilihat dari segi sikap mental orang terhadap tugas dan tanggung jawab

Dari uraian di atas dapat disintesiskan iklim organisasi adalah suasana yang timbul dalam organisasi yang dapat dirasakan atau mempengaruhi sikap, tingkah laku anggota organisasi dalam melaksanakan tugasnya.

\section{Organizational Citizenship Behavior (OCB)}

OCB memiliki banyak bentuk seperti yang dikemukakan Fred Luthans (2011:149) "organizational citizenship bahviors/OCBs can take many form, but the major ones could be summarized as : (1) altruism (e.g. helping out when a coworker is not feeling well). (2)conscientiousness (e.g. staying late to finish the project), (3) civic virtue (e.g. volunteering for a community program to represent the firm), (4) sportsmanship (e.g. sharing failure of a team project that would have been successful by following the member's advice), and (5) courtesy (e.g. being understanding and empathetic even when provoked).

Bentuk-bentuk OCB itu banyak, tetapi yang paling utama adalah (1) altruism, (misalnya membantu rekan kerja dalam menyelesaikan pekerjaannya dengan baik), (2) conscientiousness (misalnya kesadaran untuk menyelesaikan proyek/pekerjaan sampai 
selesai), (3) civic virtue (misalnya sukarela dan berpartisipasi aktif dalam kegiatan organisasi, (4 ) sportsmanship (misalnya menggambarkan pekerja yang lebih menekankan untuk memandang aspek-aspek positif dibanding aspek-aspek negative dari organisasi), dan (5) courtesy (misalnya pemahaman dan rasa empati, meringankan permasalahan-permasalahan berkaitan dengan pekerjaan yang dialami orang lain).

Jhon R. Schermerhorn (2010:68) juga menjelaskan adalah "organizational citizenship is a willingness to "go beyond the call of duty" or "go" the extra mile" in one's work". OCB adalah kesediaan untuk melampaui panggilan tugas atau ekstra dalam pekerjaan seseorang. Kreitner dan Kinicki (2010:174) menyatakan "organizational citizenship behavior consist of employees behavior that are beyond the call of duty. Examples include "such as gestures as constructive statements about the department, expression of personal interest in the work of others, suggestions for improvement, training new people, respect for the spirit as well as the letter of housekeeping rules, care for organizational property, and punctuality and attendance well beyond standard or enforceable levels. organizational citizenship behavior (OCB) terdiri dari perilaku individu diluar tugas pekerjaanya. Seperti memberikan saran yang membangun, membantu meningkatkan sumber daya manusia, mengarahkan karyawan baru, menghormati ketentuan-ketentuan organisasi, peduli terhadap property organisasi serta berprilaku melebihi tingkat standar yang ditetapkan.

Dari uraian di atas dapat disintesiskan OCB adalah perilaku individu yang mencerminkan perilaku warga organisasi yang baik, muncul secara sukarela melampaui tugasnya tanpa mengharapkan imbalan dan memberikan kontribusi demi kebaikan organisasinya.

\section{METODE}

Penelitian dilakukan pada Madrasah Aliyah Swasta di Wilayah Tangerang Raya pada bulan April sampai dengan Agustus 2013. Peneltian ini dilaksanakan dengan menggunakan metode survei dan kausal dengan menggunakan teknik analisis jalur (path analysis) yang akan menjelaskan keterkaitan antar variabel dengan variabel lainnya. Populasi dalam penelitian ini adalah kepala sekolah pada Madrasah Aliyah Swasta di Tangerang raya. Untuk mengambil sampel menggunakan simple random sampling. Sampel sebanyak 74 kepala sekolah.

\section{HASIL DAN PEMBAHASAN}

\section{Pengaruh Iklim Organisasi Terhadap Produktivitas}

Berdasarkan hasil perhitungan diperoleh koefisien korelasi $r_{13}=0,709$ dan koefisien jalur $\mathrm{p}_{31}=0,587$. Dengan demikian terdapat pengaruh langsung positif iklim organisasi terhadap produktivitas.

Hal ini sesuai dengan teori yang dikemukakan oleh Ms.Gitali Choudhury Iklim organisasi merupakan faktor kunci untuk menjelaskan keinovatifan karyawan. Jika iklim sehat, karyawan akan lebih inovatif dibandingkan dengan organisasi lain dengan iklim stress. Iklim yang baik dan sehat meningkatkan tingkat produktivitas karyawan. Jika seorang karyawan memiliki perasaan dan keyakinan tentang suasana yang ada dalam organisasi adalah menyenangkan, saling mempercayai, tidak adanya konflik, hubungan antar personal berjalan dengan baik, pekerjaan saling mendukung sehingga menjadi lancar, maka yang terjadi akan meningkatkan semangat kerja, 
mengembangkan dan meningkatkan kreativitas para personal di organisasi sehingga meningkatkan produktivitas dan efektivitas kerja

\section{Pengaruh Organizational Citizenship Behavior (OCB) terhadap Produktivitas}

Berdasarkan hasil perhitungan diperoleh koefisien korelasi $\mathrm{r}_{23}=0,550$ dan koefisien jalur $\mathrm{p}_{32}=0,213$. Dengan demikian terdapat pengaruh langsung organizational citizenship behavior (OCB) terhadap produktivitas.

Seperti dijelaskan Colquitt dkk et al,." citizenship behavior which is defined as voluntary employee activities that may or may not be rewarded but the contribute to the organization by improving the overall quality of the setting in which work takes place". Organizational citizenship didefinisikan sebagai kegiatan-kegiatan yang dilakukan oleh individu secara sukarela tanpa menuntut imbalan tetapi memberikan kontribusi pada organisasi dengan meningkatkan kualitas di tempat kerja.

Organizational citizenship behavior (OCB) merupakan perilaku yang mencerminkan warga organisasi yang baik, sadar akan hak dan kewajibannya terhadap organisasi, membela dan menjaga martabat organisasi tanpa pamrih, patuh dan taat dalam menjaga aturan organisasi, merawat property organisasi serta berprilaku melebihi harapan yang normal dalam pekerjaan mereka. OCB ini merupakan modal dasar yang sangat penting dalam meningkatkan produktivitas kepala sekolah, sebab perilaku seperti ini mencerminkan sense of belonging yang tinggi terhadap organisasinya. Jika kepala sekolah sudah sampai pada tahap ini maka loyalitas dan dedikasinya tidak dapat diragukan lagi. Jadi, pengaruh organizational citizenship behavior (OCB) terhadap produktivitas bersifat langsung.

\section{Pengaruh Iklim Organisasi terhadap organizational citizenship behavior (OCB)}

Berdasarkan hasil perhitungan dapat diperoleh koefisien korelasi $r_{12}=0,575$ dan koefisien jalur $p_{21}=0,575$. Dengan demikian terdapat pengaruh langsung positif iklim organisasi terhadap organizational citizenship behavior (OCB).

Mullins menjelaskan adalah "organisational climate will influence the level of morale and attitudes which members of the organisation bring to bear on their work performance and personal relationships". Iklim organisasi akan mempengaruhi tingkat moral dan sikap yang anggota organisasi bawa untuk melahirkan kinerja kerja dan hubungan pribadi mereka. Hal ini tampak jelas bahwa ketika seseorang memiliki rasa memiliki organisasi tersebut dan tanggung jawab maka secara otomatis akan memberikan dukungan terhadap individu lainnya. Ketika dukungan antara individu terjadi maka akan berakibat pada kehangatan di dalam organisasi. Kondisi tersebut akhirnya memunculkan prilaku untuk membantu orang lain dalam hal pekerjaannya, taat terhadap peraturan organisasi, menghormati orang lain dan memiliki rasa tanggung jawab yang tinggi.

Untuk menghasilkan organizational citizenship behavior (OCB) yang baik membutuhkan iklim organisasi yang kondusif, sebaliknya iklim organisasi yang tidak kondusif dapat mendorong tidak terwujudnya organizational citizenship behavior (OCB). Dengan demikian dapat dikatakan bahwa iklim organisasi menentukan baik/buruknya organizational citizenship behavior (OCB). 


\section{PENUTUP}

Kesimpulan. Berdasarkan hasil penelitian ini dapat disimpulkan bahwa :

1. Terdapat pengaruh positif iklim organisasi terhadap produktivitas ditentukan oleh derajat besarnya pengaruh dalam bentuk koefisien korelasi dan koefisien jalur. Nilai koefisien jalur menentukan besaran varians produktivitas ditentukan oleh iklim organisasi. Selanjutnya dapat diketahui signifikansi pengaruh antara iklim organisasi terhadap produktivitas parsial. Hal ini memiliki makna dan penegasan bahwa iklim organisasi secara empiris bukan satu-satunya variabel prediktor bagi varians skor produktivitas.

2. Terdapat pengaruh positif organizational citizenship behavior (OCB) terhadap produktivitas yang ditentukan oleh derajat besarnya pengaruh dalam bentuk koefisien korelasi dan koefisien jalur. Nilai koefisien jalur menentukan besaran varians produktivitas ditentukan oleh organizational citizenship behavior (OCB). Selanjutnya dapat diketahui signifikansi pengaruh antara organizational citizenship behavior (OCB) terhadap produktivitas secara parsial. Hal ini memiliki makna dan penegasan bahwa organizational citizenship behavior (OCB) secara empiris bukan satu-satunya variabel prediktor bagi varians skor produktivitas.

3. Terdapat pengaruh positif iklim organisasi terhadap organizational citizenship behavior (OCB).

Saran. Berdasarkan hasil penelitian beberapa hal yang disarankan bagi perwujudan dan peningkatan produktivitas kepala sekolah sebagai berikut:

1. Para pengambil keputusan hendaknya memperhatikan masalah iklim organisasi, dan organizational citizenship behavior (OCB) dalam rangka meningkatkan produktivitas kepala sekolah. Selain itu, ternyata masih banyak variabel lain yang berpengaruh langsung terhadap produktivitas kepala sekolah. Pemahaman tentang produktivitas kepala sekolah akan membantu para pengambil keputusan dalam mewujudkan tujuan organisasi bersama-sama dengan kepala sekolah.

2. Para kepala sekolah Madrasah Aliyah swasta di wilayah Tangerang Raya hendaklah secara aktif meningkatkan produktivitas kepala sekolah dalam menjalankan peranan dan tanggung jawab sebagai kepala sekolah. Hal ini dapat dilakukan dengan peningkatan iklim organisasi, dan organizational citizenship behavior (OCB). Upaya peningkatan produktivitas kepala sekolah yang dimaksudkan agar setiap kepala sekolah sebagai individu menyadari mengenai keadaan dan pekerjaannya yang menjadi tanggung jawabnya 


\section{DAFTAR RUJUKAN}

Andre, Rae, Organizational Behavior, New Jersey : Pearson Prentice Hall, 2008

Cardoso Gomes, Faustino, Manajemen Sumber Daya Manusia, Yogyakarta : Penerbit Andi, 2003

Colquitt, Jeffery A.Lepine, Michael J.Wesson, Organizational Behavior Improving Performance and Commitment in The Workplace, Second Edition, New York : McGraw Hill Irwin, 2009

Darsono dan Tajuk Siswandoko, Manajemen Sumber Daya Manusia, Jakarta: Nusantara Consulting, 2011

Dyck, Bruno dan Mitchall J.Neubert, Principles of Management, South Western : Learning, 2009

Kreitner dan Kinicki, Organizational Behavior, Ninth Edition, New York : McGraw Hill, 2010

Luthans, Fred, Organizational Behavior. An Evidence-Based Approach, Twelfth Edition, New York : McGraw-Hill, 2011

Luthans, Fred, Organizational Behavior Twelfth Edition, New York : McGraw-Hill, 2011

Luthans, Fred, Organizational Behavior Twelfth Edition, New York : McGraw-Hill, 2011

M.Ivancevich, John, dan Robert Konopaske, Human Resources Management, New York: McGraw-Hill, 2013

McShane dan Von Glinow, Organizational Behavior Emerging Knowledge and Practice For The Real World, New York : McGraw Hill, 2010

Mullins, Laurie J, Management and Organizational Behavior Seventh Edition, England : Financial Times, 2005

Raharjo, Joko, Paradigma Baru Manajemen Sumber Daya Manusia, Jakarta : Platinum, 2013

Robbins Stephen P, dan mary Coulter, Management, New Jersey : Prentice Hall, 2009

Robbins, Stephen P, dan Timothy A. Judge, Organizational Behavior Fourteenth Edition, New Jersey : Prentice Hall, 2011

Schermerhorn, John R, JR, Introduction to Management Ten Edition, USA : John Wiley \& Sons, 2010

Soetopo, Hendayat, Perilaku Organisasi, Bandung : PT Remaja Rosdakarya, 2010 
Sonnentang, Sabine, Psychologycal Management of individual performance a Handbook in the Psychology of Management in Organizations, New York: John Wiley and Sons. Ltd, 2002

V G Kondalkar, Organizational Behavior, New Delhi : New Age International Publishers, 2007 
